\title{
Civil Society Activism in Italy Across Different Fields: A Multifaceted Picture of Solidarity in Hard Times
}

\section{Nicola Maggini and Veronica Federico}

\section{Introduction}

In Italy, the global economic crisis had a devastating impact on fragile populations. It created new important waves of unemployed and worsened the conditions of those who were already suffering from unemployment. Especially during the 2010-2013 period, it led to severe cuts in welfare services, which negatively affected the most vulnerable sectors of society, such as people with disabilities. Furthermore, since 2014 the refugee crisis has dramatically and suddenly raised the number of migrants, thus increasing the areas of intervention, especially in the field of political asylum. Despite this difficult context, a web of civic engagement sustained by civil society organisations has been working on

\footnotetext{
N. Maggini $(\bowtie)$

Robert Schuman Centre, European University Institute, Fiesole, Italy e-mail: nicola.maggini@eui.eu

V. Federico

Department of Legal Sciences, University of Florence, Florence, Italy e-mail: veronica.federico@unifi.it 
a daily basis to mitigate the impact of economic breakdown and austerity policies, taking the form of both advocacy and a service provision. Therefore, civil society engagement has been functioning to complement the welfare state, a most essential role for the most vulnerable people (Baglioni and Giugni 2014).

Austerity and cuts led not only to anti-austerity protests but also to resilience and social ingenuity, deployed through a range of civil society organisations, social movements and social innovations according to empirical studies on solidarity initiatives both in Italy and in Europe (Andretta and Guidi 2014; Forno and Graziano 2014; Grasseni 2014; Kousis and Paschou 2017; Oliveri 2015; Kousis et al. 2018; Lahusen et al. 2016). Furthermore, as stressed by some of these studies (Forno and Graziano 2014; Bosi and Zamponi 2015), during the crisis many Italian social movement organisations and activists altered their repertoire of actions at the local level in order to achieve social change. They seem to have abandoned the tactics of large protest events, as they did in previous years, and started to focus on small-scale everyday solidarity activities in order to transform society from below.

Moreover, the refugee crisis has accentuated the importance and growth of transnational solidarity organisations (TSOs) (Ataç et al. 2016). Older movements, such as the disability movement or the unemployment/labour movements, also illustrate the importance of transnational solidarity and the impact of the economic crisis. Indeed, the increasing importance of transnationalism has been noted by the development of transnational-focused disability critical literature (Shildrick 2009; McRuer 2010; Soldatic and Grech 2014).

Against this backdrop, this chapter is devoted to monitoring, analysing and assessing practices of Italian transnational solidarity organisations, such as citizens' initiatives and networks of cooperation among civil society actors (for instance, NGOs, churches, voluntary associations and cooperatives), in response to the crises, focusing on three fields of activity: disability, unemployment and migrants. The aim is to investigate the relationship between the organisational field and its environment (the crises), and the level of contentiousness, innovativeness and transnationalism of each issue-field. In this regard, we focus on differences and similarities among migration, disability and unemployment TSOs in terms of 
approaches followed (such as top-down vs. bottom-up) and type of solidarity provided (e.g., help/service-oriented TSOs vs. protest/policyoriented TSOs), aims and perceptions of the economic crisis and the spread of international linkages.

Our main hypothesis is that solidarity in the three policy domains is strongly determined by the very field of activity, since policy domains influence TSOs' perceptions of the economic crisis, their approaches and their level of contentiousness and transnationalism. Solidarity is domainbounded (Warren 2001). Secondly, we postulate that the economic crisis may represent a vector of innovation (Bosi and Zamponi 2015) and of transnationalism, pushing Italian TSOs to look for new strategies, approaches, collaborations and geographical perspectives. Prior literature has discussed whether unexpected events, such as a crisis, are opportunities for organisational learning (Carley and Harrald 1997). In this regard, a study concerning the impact of the crisis on civil society organisations in the European Union (EU) (Shahin et al. 2013) has shown how the crisis implied particularly severe financial constraints for civil society organisations in Southern Europe. Indeed, the huge cuts in government spending have affected them directly, given that they were traditionally dependent on government funds. As a reaction to this changing environment, Southern European civil society organisations have expanded their collaborative networks (particularly in the field of social services) or acceded to EU funds (by participating in projects) as a means of ensuring steady funding.

The chapter elaborates on the data gathered through 30 in-depth interviews (10 from each target group) with representatives of innovative, informal Transnational Solidarity Organisations (TSOs) (Kousis et al. 2018) in Italy, carried out mostly in September-October 2016, under the TransSOL project (TransSOL 2016). ${ }^{1}$ When compiling the sample, ${ }^{2}$ we sought to take into account regional variety across the country. However, it transpired that mostly TSOs from the centre and the north of Italy were willing to participate in this study, while TSOs from the south of

\footnotetext{
${ }^{1}$ This project has received funding from the European Union's Horizon 2020 research and innovation programme under grant agreement No. 649435.

${ }^{2}$ For more information on sampling, see https://blogs.uni-siegen.de/transsol/files/2016/12/ Integrated-Report-on-Reflective-Forms-of-Transnational-Solidarity.pdf
} 
Italy were very difficult to convince. ${ }^{3}$ As regards the type of TSOs selected, most of our interviewees belong to voluntary, non-profit organisations with no or very few paid staff, followed by local or regional branches of religious organisations, and (mainly (un)employment-oriented) cooperatives and a trade union. Finally, we also interviewed a representative of an informal grassroots movement and an alternative media network (see also Maggini and Federico 2016).

The chapter will first provide a general overview of a variety of challenges TSOs have had to face in Italy as a consequence of the economic and refugee crises, looking at how the TSOs describe the legal and policy context in which they are embedded. Secondly, it will investigate TSOs' activities, focusing on TSOs' approach, missions and target groups, innovativeness, type of solidarity provided, detecting differences and similarities between policy domains. Thirdly, it will explore forms, reasons and rationales of TSOs' cooperation with other civil society organisations, with public authorities and, finally, with foreign or international actors. In conclusion, we will discuss the two assumptions the present chapter is based on through the lens of our analysis.

\section{TSOs' Descriptions of the National Context with Its Core Challenges}

The economic and refugee crises have had a tremendous impact on Italian TSOs' activities across the three fields. All interviewees highlighted the difficulties created or exacerbated by the economic crisis. Reflecting on the consequences of the crisis for both the beneficiaries and the organisations themselves, they mentioned welfare cuts, a reduction in public funds and donations, a reduction in employment levels and so on, but some added interesting insights, unveiling less patent implications ${ }^{4}$ :

\footnotetext{
${ }^{3}$ We could postulate that the reluctance of Southern Italian TSOs might be due to the fact that Southern Italy may be described as a typical low trust society, where the scarce presence of social capital engenders a low level of "trust in others" (Banfield 1967).

${ }^{4}$ Several interviewees mentioned the cuts to the "National Fund for the Non-Self-Sufficient" (in 2011 this fund was reduced by $75 \%$ due to budget cuts and only in 2015 was the fund brought back to its original 400 million euros).
} 
Independence and autonomy are linked to the economic situation ... The disabled person has daily needs. The life of a disabled person's family is also affected economically. Disability may create difficulties also from a professional standpoint ... In addition, the disabled often have to buy new houses for their needs ... The disability or illness in itself has a differentiated impact depending on the economic situation of the disabled person's family. The crisis broadens these inequalities. (Disab5 10/2016)

Austerity policies enacted in the EU are generally strongly criticised:

In Europe, the contradictions between countries have led to the wrong policy of austerity, unlike the US whose economy has grown. (Unemp2 09/2016)

The rigour of the EU has failed. (Unemp6 10/2016)

The Italian approach presents critical aspects, too, for instance, with regard to the lack of provision of a basic income ${ }^{5}$ and the absence of a "serious, robust industrial policy" ${ }^{6}$ Moreover, the pursuit of flexibility, the fragmentation of the labour market and the dearth of investments to boost research were also pointed out as Italian weaknesses. ${ }^{7}$ To sum up:

The measures were not sufficient enough to cover the surge of new forms of poverty generated by the crisis. The interventions are too sectoral, and we lack a systematic approach. (Unemp7 10/2016)

Nonetheless, some interviewees mentioned the positive effects brought about by the enforcement of new policies and legislation like agribusiness protection, the reduction of taxes on social cooperatives and the part of the "Jobs Act" that fiscally favours permanent contracts.

\footnotetext{
${ }^{5}$ Unemp10 10/2016.

${ }^{6}$ Unemp6 10/2016.

${ }^{7}$ Unemp2 09/2016.

${ }^{8}$ The Jobs Act is the name of the labour market reform undertaken to face the crisis. It consists of two framework pieces of legislation (Law Decree no. 34 of 2014 and Law no. 183 of 2014) and a number of additional law decrees have radically redefined the legal framework of the labour market with the purpose of simplifying, revising the regulation of employment contracts and improving
} 
Against the backdrop of a generalised, obvious perception of the economic crisis as the cause of worsening socio-economic conditions, TSOs' understanding of the context they are embedded in varies largely along the policy domain they are active in. Disability TSOs stressed the coherence of the legal and policy framework, but they highlighted that the economic crisis had aggravated policy and law implementation and contributed to a decrease in available funds and the related capacity to deliver services for disabled people. In this field, very few were the voices claiming the crisis as a challenge to innovate and induce positive transformations. In recent years, some new and important legislation has been enforced. Of particular relevance is the law dopo di noi-after us, taking care of severely disabled persons after the death of their family members, and the reorganisation of the third sector, which has an indirect but strong impact on services. However, all the TSOs asserted that the problem does not lie with legislation's deficiencies but mainly lies with its sound implementation. ${ }^{9}$ Interestingly, some assert that Italian devolution in the health sector has produced inequality of treatment:

The Region of Tuscany recognises twice as many rare diseases than the rest of Italy. We are lucky. But those who live in other regions, especially the poorest ones, are disadvantaged. (Disab4 10/2016)

Some interviewees also highlight a specific failure by the Italian legal framework to guarantee job placement for disadvantaged workers:

the work-life balance. Among other things, passive and active labour market policies have been reformed, a new form of a permanent contract with increasing protection levels has been launched and a new unemployment benefit scheme has been put in place. Article 18 of the Workers' Statute, imposing restrictive conditions for workers' dismissal, has been radically reviewed, eliminating the system of compulsory reintegration in case of unjustified dismissal for workers employed under the new contract system. Increased levels of job protection depend on seniority and are based on monetary compensation (instead of compulsory reintegration). Opinions on the Jobs Act are, however, controversial: Some (especially the cooperatives) accept flexibility if accompanied by social protection and active labour market policies, while for others (specifically the unions), the flexibility is absolutely negative, as it leads to dismantling workers' rights.

${ }^{9}$ Disab5 10/2016. 
It is an outdated law, ill-suited to favour and guarantee the employment of disadvantaged people. It is based on a medical definition of 'disadvantage', certified by health services, and this is a very resizing approach. (Unemp3 09/2016)

In comparison, TSOs active in the unemployment field severely criticise both a fragile and inadequate legal and policy framework and a weak industrial and economic infrastructure. However, in contrast to disability TSOs, many interviewees from unemployment TSOs also perceive the crisis as an opportunity to innovate the welfare system and to develop a solidarity-based local economy. And this was perceived as a positive legacy of the crisis:

Many people have rediscovered agricultural and handicraft activities, with the effect of making the economic system stronger at the local level. (Unemp5 10/2016)

I am not pessimistic. Not everything depends on us, but a good deal! (Unemp6 10/2016)

At the same time, it is within the unemployment TSOs that there is the highest variance in the perception of the Italian government's policy responses, with a clear contraposition between cooperatives and social enterprises more open to consider some positive aspects of policy reform, and trade unions and left-wing organisations fiercely against those same measures. In fact, optimism is not shared by everyone. Reflecting on rights protection and enforcement, especially socio-economic rights, one interviewee from a more critical TSO observed that: "Crises always lead to regressive phenomena” (Unemp2 09/2016).

In the immigration/refugee domain, our interviewees underline that the crises, and especially the "refugee crisis", brought to the forefront the legal weaknesses of a very fragmented, fast-changing legal framework. At the same time, the "refugee crisis" altered the funding opportunities for TSOs. Since the beginning of 2016, there has been a significant increase in both the number and the funding of projects and tenders, mainly concerning services for immigrants and refugees. In fact, the creation of the 
Italian Agency for development aid in 2016 and the increased funds for international cooperation were also mentioned as important innovations. ${ }^{10}$ Nevertheless, most interviewees emphasise that the Italian legal framework in this field is deficient. There is no clarity on quotas and regulations, and laws are often not enforced. Legally entering the country is difficult; thus, many migrants turn to criminal organisations, and asylum applications are often abused as they are perceived as the sole measure to enter Italy legally.

In particular, interviewees strongly criticise the EU-Turkey Agreement on refugees with no guarantee of human rights' respect, ${ }^{11}$ the prohibition of monitoring the hotspots' system by activists to oversee the procedural correctness, ${ }^{12}$ the lack of a real common migration policy at an EU level and the lack of solidarity among member states as regards the relocation of refugees. ${ }^{13}$ Conversely, some judgements of the European Court on Human Rights are considered as positive (for instance, the prohibition of collective expulsions of aliens has been extended to migrants intercepted at sea). The problem highlighted by the interviewees is that often courts' judgements remain on paper and are not implemented. The attitude of the then centre-left Italian government under Matteo Renzi is perceived as more positive than that of Eastern European governments. Particularly appreciated is the operation of migrants' sea-rescue. ${ }^{14}$ However, interviewees denounce the lack of a strategic and coherent plan to receive migrants and the slowness of the asylum proceedings.

In terms of public opinion attitudes, our interviewees generally do not perceive hostility towards immigrants in their local contexts, ${ }^{15}$ except in a northern city:

\footnotetext{
${ }^{10}$ Migr6 10/2016.

${ }^{11}$ Migr6 10/2016 and Migr8 10/2016.

${ }^{12}$ Migr8 10/2016.

${ }^{13}$ All interviewees.

${ }^{14}$ These considerations pertain to the government of the time of the interviews. The entering into force of a new executive, after March 2018 general elections, radically changed the migration policy. The closure of ports for non-governmental organisations' rescue missions and push backs became the flagship measure of the new government immigration policy under the coalition of the Five Star Movement and the right-wing party The League of the time.

${ }^{15}$ It is crucial to point out here that since the interviews, the political and public opinion climate has changed dramatically. The large consensus obtained by the xenophobic party The League in the
} 
Here, there is hostility towards immigrants. And after the terrorist attacks, even fear. (Migr5 09/2016)

Some also emphasise the importance of breaking down the walls of distrust and promoting solidarity, to mobilise local communities and to build a multi-ethnic society. In comparison, others highlight the risk that the weakness of the Italian welfare state could trigger a struggle among the poor.

In contrast to these field-specific context conditions, some important similarities of the three fields have emerged from our interviews. Beyond the criticism and the dire socio-economic conditions, the economic crisis is depicted by several interviewees in all three domains also as an opportunity, in particular as an opportunity to reconsider their views and to retrain and increase cooperation between associations. For instance, in the disability field, many interviewees say the crisis pushed them to develop new strategies based on networks of solidarity and to overcome the excessive particularism and parochialism that has long characterised the field dominated by highly disability/disease-specialised organisations. ${ }^{16}$ In fact, it was exactly the lack of funding that triggered many TSOs to collaborate with other civil society organisations in their field in order to share resources. Similarly, the crisis opened the door for unemployment and refugee TSOs towards new horizontal relationships among TSOs, driving them to engage in tighter and more effective cooperation in order to face the new challenges in times of crisis. In addition to interorganisational coalition building, the crisis has also forced associations and public authorities into tighter cooperation to compensate for the lack of resources and to minimise costs. However, these new opportunities are not easy to grasp, and state intervention is still considered necessary:

Where there is a vacuum, there is always an opportunity, but it is difficult in practice. NGOs should not replace the state. (Migr6 10/2016)

2018 general elections and in the 2019 European elections on a political platform based on "Italian First" policy is a clear marker of this change in public opinion.

${ }^{16}$ Disab9 10/2016 and Disab10 10/2016. 
Our motto is: We are born to die. Our aim is to oblige the institutions to do what we do today. (Migr4 09/2016)

In this regard, some interviewees in both the unemployment and the disability fields stress the importance of subsidiarity. This does not mean that civil society organisations should replace the state. Instead, TSOs advocate for a fruitful collaboration between the state and the third sector, especially in welfare services' delivery:

The future is subsidiarity, however, the state must implement measures to promote job placement. (Unemp3 09/2016)

In other words, a new civil society activism should not be an excuse for public authorities to negate their responsibility by not providing welfare services. Moreover, "if the state has less money, you could activate solidarity from below. But this happens only where there is a favourable cultural substratum" (Disab5 10/2016).

\section{Activities: Missions and Target Groups}

Against the backdrop of common overarching, broad goals of the interviewed TSOs in the three fields under review (combating discrimination, helping others and promoting social integration), we have observed a certain variation in terms of the type of solidarity provided and approach followed depending on the policy domains, detecting differences and similarities. The pattern of differences and similarities is neither regular nor homogeneous across the fields.

\section{TSOs' Approach}

In both the unemployment and the disability fields, most of the TSOs choose the top-down approach of providing goods and services to their beneficiaries, but at the same time, they offer solidarity activities based on mutual help and support between groups (especially in the disability 
field). Indeed, almost all TSOs in the disability sector are formed of disabled people and their families (and one of them was originally a self-help group which turned into a non-profit organisation). Thus, many interviewees either are disabled people or are relatives of people with disabilities:

I decided to join the association to seek answers. My daughter is afflicted by multiple sclerosis. (Disab3 09/2016)

I joined 26 years ago for personal reasons: my son has spina bifida. The association has filled an absolute void that we as parents experience [...] It provides real opportunities that allow us to work not only for our child, but also for others, and this is gratifying. It is a healthy selfishness. (Disab4 10/2016)

Similarly, mutual help characterises many TSOs within the unemployment field, especially cooperatives and trade unions. Conversely, only one of the migration TSOs provides solidarity activities based on mutual help, a migrants' association that pursues the promotion of Arab culture and intercultural exchanges to raise awareness of Moroccan culture among the second generation of immigrants and to defend women's rights. This difference with respect to the other fields can be explained by the fact that most of the TSOs in the migration field that have been interviewed are formed by Italians, not by immigrants. In this regard, scholars have stressed the contentious and thus political nature of many solidarity movements across the globe that address refugee and migrant needs (Ataç et al. 2016). Thus, it is unsurprising that belonging to migration TSOs is driven, above all, by political-ideal motivations rather than by mutual help between people of the same ethnic background.

\section{TSOs' Mission}

A large majority of interviewed TSOs tend to combine services providing and advocacy and public awareness raising, but the level of engagement in the two activities, the kind of services and the type of advocacy are different in the three policy domains. 
Predictably, the picture of services offered to their beneficiaries is quite diverse among and within each issue-field. As regards migration TSOs, they offer services of first and second reception, legal advice, medical care, training and job placement, Italian language courses, Arabic courses for second-generation speakers, information activities (conferences, seminars, reports, videos, radio) and activities to increase public awareness of migrants' rights, lobbying and influencing, projects promoting fair trade and international cooperation, social communication projects, training for lawyers and social workers, intercultural dialogue and exchanges, and so forth.

Similarly, disability TSOs provide a rather diverse range of services: personal services (home support, counselling, home physiotherapy, sports and Shiatsu massages for the disabled), information activities (conferences, seminars, magazines, websites) and activities to increase public awareness, training of volunteers, conferences and seminars for doctors, donations to research, specialist training, specialised libraries and disability resource centres, school and job placement, selection of technological aids, fiscal services, calculation of pensions, legal/medical advice, support for the aggravation of a disease and its legal recognition, information points in hospitals, and so forth.

Finally, the typical activities and services provided by unemployment TSOs are disadvantaged people's work placement (e.g., through the collection and supply of medical mobility devices, the production and sale of organic fruit and vegetables), political and union workers' representation, political and union cooperatives' representation, business services (such as legal and financial services), staff retraining, job training, information campaigns and political mobilisation through the radio, and the like.

When the analysis moves to the balance between service providing and advocacy activities, an interesting difference emerges between disabilityrelated TSOs on the one hand and TSOs within the unemployment field on the other. While in the disability field TSOs are focused more or less equally on both service delivery and lobbying, in the unemployment field there is a clearer distinction between organisations that prioritise either help and service orientation (religious organisations and social cooperatives) or protest and policy orientation (e.g., an alternative radio network, 
a trade union and a league of cooperatives). The former are more interested in providing services to their beneficiaries, whereas the latter are more concerned with lobbying and political issues, having also more general aims linked to social change, economic democracy and social justice.

Between these two poles, there is the migration field, where some organisations are more help-oriented (especially religious organisations and social cooperatives), whereas others are more policy-oriented and reflect a more contentious approach (especially the informal grassroots group and, to a certain extent, some non-profit organisations). However, even those more help-oriented organisations are interested in lobbying and advocacy, and those more policy-oriented ones also provide concrete help to migrants and refugees.

Here again, the field of activity does not simply influence the kind of services provided by TSOs (and this is predictable), but it also influences the blend of services and advocacy and, finally, their approach to lobbying and advocating.

\section{Beneficiaries}

Across the three issue-fields, TSOs' beneficiaries are mainly local and regional residents and, to a smaller extent, national ones, even in the migration field, with the exception of a few TSOs that are also very active abroad, caring for migrants and refugees in other countries (or in their country of origin).

Unsurprisingly, TSOs' solidarity actions are oriented towards beneficiaries belonging to their issue-field: For unemployment TSOs, the target groups are the unemployed (both in general terms and within special groups of unemployed), workers and (in one case) cooperatives; within the migration field, the target groups are, obviously, migrants, refugees, asylum seekers and persons in need of international protection, and finally for disability TSOs, the target groups are disabled people and their families.

Nevertheless, there are some beneficiaries crosscutting issue-fields. This especially affects TSOs within the unemployment field: Among the disadvantaged unemployed, there are physically and mentally disabled, 
drug addicts and detainees. Moreover, most of the interviewed TSOs in the unemployment field have foreign people among their beneficiaries, and a local chapter of a religious organisation deals with migrant job orientation and training. Within the migration field, some organisations also deal with victims of torture, female victims of trafficking, unaccompanied minors and ethnic minorities (Roma and Sinti). Most of the TSOs are not focused on a specific ethnicity, with the exception of the aforementioned migrants' association founded by Moroccan women. In short, its solidarity actions are not exclusively directed towards members of the association:

We are open to everybody: men and women, both Italian and of Arab culture. (Migr9 10/2016)

Conversely, in the disability field the target groups are only the disabled and their families. Nonetheless, (almost) all the TSOs of our sample have foreigners as beneficiaries, members or volunteers. Foreign people with disabilities face additional problems and difficulties (such as claiming for family reunification). Interviewees recognise that disabled migrants come to Italy because in their country their right to health and to a decent life is not guaranteed. This is particularly true for migrants afflicted with rare diseases. Many interviewees also stressed that foreigners are often single women showing an untrusting and diffident attitude, revealing an instrumental approach towards the association:

They take everything they need and then disappear. They hardly take part in the life of the association [...] This is because they think that one day we can ask back what we have offered [...] They are not aware of their rights. (Disab4 10/2016)

Very interestingly, only a few TSOs are involved in solidarity activities towards disabled people as such, whereas most of TSOs are focused on specific disabilities: the blind, people with hydrocephalus and spina bifida, people affected by multiple sclerosis, people with SLA, maimed people. This reveals a strong specialisation and sectorialisation, increasing the risk of the fragmentation of disabled people's interests. Harsh 
competition for private and public financial resources is another serious consequence of this fragmentation. Many activists are conscious of these dangers:

In Italy associations in the field of disability are still highly fractioned along pathologies and forms of disability. This is quite obvious on the one hand, but problematic on the other because it tends to prevent the establishment of a strong group of interest, whose voice could be louder in the public sphere. If we were less divided, we could achieve more strategic goals. (Disab1 09/2016)

There is the risk that everyone just thinks of his/her own backyard with a war among the poor. (Disab6 10/2016)

There is the danger of particularism and 'trends', if each association focuses on its own benefits and backyard [...]. This is a problem for true solidarity. (Disab4 10/2016)

In terms of solidarity, what is interesting, however, is that the sectorialisation of disability TSOs does not match with a chauvinistic "promembers" attitude: In most cases, these solidarity actions towards people with (specific) disabilities are not exclusively restricted to the association's membership (although members sometimes receive special treatment). ${ }^{17}$ Membership is not very important in terms of financing (membership fees are often nothing more than symbolic). Membership remains relevant, nonetheless: "The members' weight is of crucial importance in lobbying and campaigning" (Disab3 09/2016). Moreover, "membership is important to develop a sense of belonging to the group" (Disab4 10/2016). But "some members instrumentally join the association for individual goals rather than for collective ones" (Disab2 09/2016).

\section{Innovativeness}

Regardless of the issue-field, the majority of interviewed TSOs developed innovative practices as a response to societal challenges such as the

${ }^{17}$ Disab2 09/2016. 
economic and refugee crisis, austerity measures and welfare retrenchment. Most of our interviewees across the three fields say that they have produced innovative solutions to meet the increasing needs of their beneficiaries in terms of content, communication and kind of help offered, as highlighted by several interviewees in the unemployment field:

Our organisation was created around the innovative idea of providing medical mobility devices at a controlled price meeting a local need. (Unemp3 09/2016)

The most innovative project is a business project of local farming products that are marketed on a web portal [...] It works pretty well. (Unemp5 10/2016)

In response to the crisis, we support the transformation of workers from companies in financial crisis into co-operators, that is, into collective entrepreneurs. (Unemp6 10/2016)

Innovativeness in solidarity activities has been fostered by the crisis also in the disability field. Only two interviewees explicitly affirmed that their activities do not present any innovativeness, whereas another interviewee maintained that innovative activities occur at the national level (for instance, the organisation's headquarters elaborated very detailed reports on the disease and the related rights), but not at the local level.

Innovativeness is perceived either in terms of content or in terms of communication: petitions, videos, awareness campaigns with the support of national newspapers and social networks, promotional tours and theatre performances for children and so forth. Among the innovative practices: a "wheelchair tour" visiting the places where major accidents at work took place was organised by a victim of an accident at work to raise awareness of safety; the Ice Bucket Challenge largely adopted as a fundraising and awareness campaign; and a new approach to services for disabled people based not on what can be offered but on the real needs of the person. Sometimes, innovation lies in the methodology: The disabled are not simply beneficiaries, but they actively participate in every aspect of the association's life. This entails no asymmetry between helper and receiver according to a rights-based approach to foster empowerment and 
capacity building. Moreover, in one case, the very association rooted its origins in innovativeness, namely the idea of creating a documentation centre on disability 30 years ago when there were no documentation centres on disability:

Three guys thought: What can we do for society? ... and not just: What can society do for us? (Disab6 10/2016)

Most of the interviewees within the migration field also stated that their group produced innovative solutions to meet the increasing needs of their beneficiaries in terms of content, communication, kind of help offered, capacities (expressly, the launch of new practices and the development of transnational ties) and processes (especially non-institutional means). Among the most interesting and original examples are a system of diffused hospitality, where migrants are hosted in small apartments with the purpose of reducing the impact on local communities and encouraging dialogue and social inclusion, and counter-information campaigns to document the dramatic dis-homogeneity of the reception centres.

Moreover, a TSO has an interesting project to encourage entrepreneurship among migrant women in the wake of a fair trade project already developed in Morocco with the collaboration of an Italian university. The idea is to create a cooperative of women based in an Italian city that will run a "Moroccan-style Hamman" using cosmetics (especially the famous Argan oil) produced by a partner women's cooperative in Morocco. Finally, a group of independent journalists and activists launched an innovative political and social campaign along the migratory routes in the Balkans and in Greece (for instance, in the refugee camp of Idomeni) to install parables providing access to $\mathrm{Wi}-\mathrm{Fi}$ for migrants to communicate with their families, submit asylum demands and mobilise from below.

From past experience, we have understood the importance of communicating for migrants. [...] Surely this campaign has been a novelty. [...] We want to build a policy agenda from below to advocate for the enforcement of fundamental rights for everyone. (Migr8 10/2016) 
This campaign is a clear example of how actions can assume different features in terms of innovativeness: as new activities resulting from a learning process, as new supporting communication and networking activities, as new activities geared to empowering, activating and integrating target groups to enable self-initiative, self-representation, self-reliance.

\section{Cooperation: Forms, Reasons and Rationales}

\section{Cooperation with Other Civil Society Organisations}

Interviewed TSOs are active at the local and regional level/s or are local branches of national organisations. In the local context, they have developed collaborative relationships with a variety of other organisations: non-profit/NGO/voluntary organisations, trade unions, cooperatives, religious organisations, grassroots movements and activists. In general, our interviewees recognise the importance and benefits of cooperation: "It is useful to work in a network perspective" (Unemp7 10/2016).

Interviewed TSOs collaborate mostly with other organisations that operate in the same policy domain. The specificity of migration TSOs emerges here: Most of these associations deal with migrants, but there are also interlinkages with other organisations like Emergency ${ }^{18}$ and trade unions, with international cooperation NGOs and with associations focusing on battered women and minors (namely Save the Children). Here, a clear difference between charity/practical help/service TSOs and protest/social movement/policy-oriented TSOs emerges. The latter cooperate regularly with informal groups, grassroots movements and squats, whereas the former cooperate primarily with formal voluntary organisations and NGOs, trade unions, cooperatives and religious organisations. This distinction relies on the fact that policy-oriented TSOs have a more contentious and political approach than charities and "practical help" TSOs.

\footnotetext{
${ }^{18}$ One of the most famous Italian independent organisations providing medical treatment to the victims of wars, landmines and poverty worldwide.
} 
Most of the disability TSOs are local branches of national organisations, and their collaborations often involve associations caring for similar disabilities. This seems to confirm the trend of the thematic specialisation of disability organisations that we discussed earlier and its inherent risk of particularism. Rarely do these associations develop collaborative relationships with organisations active in different policy domains, that being so, only one respondent disclosed their collaboration with migrant associations: "We share the theme of diversity" (Disab6 10/2016).

The exceptionality of this association is not accidental: It is one of the few organisations working on disability in general, boosted by a robust and broad understanding of solidarity, based on rights and not on charity, which may justify the interest in collaborating with entities active in different policy domains. ${ }^{19}$

\section{Cooperation with Public Authorities}

Our respondents, regardless of the issue-field, are also inclined to collaborate with public authorities, primarily municipalities and regions, as these are the government levels primarily responsible for either service delivery or policy-making in the relevant policy domains. For instance, they participate in tenders funded by local authorities aimed at providing social services, training, and job placement, and they are part of local discussion fora, bargaining tables, community services and training of caregivers and so forth. Furthermore, some migration TSOs are involved in the System of Protection for Asylum Seekers and Refugees (SPRAR) that ensures "integrated reception" activities to asylum seekers and people entitled to international protection. The SPRAR Central Service was

\footnotetext{
${ }^{19}$ We might be tempted to assume that a broader scope mission would entail a larger organisation's network and more frequent collaborations with partner organisations. However, we learn from literature (Alexander 1995: 317) that the relationship between mission scope and network characteristics is more complicated than a simple observation, since the way the mission scale and type affect the collaboration network in both quantity and quality is complex and multifaceted. Our sample is too small to inquire into such complexity, and further, a more in-depth research is required to draw reasonable conclusions. Yet we cannot abstain from observing that this seems an interesting analytical perspective.
} 
established by the Ministry of Interior-Department of Immigration and Civil Liberties-entrusting the National Association of Italian Municipalities (ANCI) with its management.

In general, our interviewees claim to have good relations with the local institutions ("They need us because they cannot meet all the needs they should care for, and we want to be part of the game to try and change the status quo" ${ }^{20}$ ) with a few interesting exceptions, especially regarding the migration area. Here, there is a clear cleavage between help-oriented TSOs, which show a more collaborative approach towards public institutions, and protest and policy-oriented TSOs, which have more confrontational and conflictual relations.

The quality of the relationship with public authorities heavily depends on the authorities' political connotation, and this is easily understandable. The most political TSOs tend to have very conflictual relations with right-wing authorities.

Having good relations with public institutions is not surprising as for TSOs within the disability and unemployment area. In these two policy domains, the cleavage between help-oriented and policy-oriented is not very relevant. In both cases, TSOs are involved in lobbying and advocacy campaigns and are not heavily politicised (with the exception of the alternative radio network that has a radical and contentious approach, based on communist ideals) and have a pragmatic and collaborative approach:

Our association is not only assertive, but also proactive. It is important to cooperate with the institutions. (Disab5 10/2016)

Interestingly, the trade union has both collaborative and conflictual relationships with political institutions, and this is in line with the typical approach of this specific union (which is a "traditional" trade union with a clear left-wing political vision) at both national and local levels.

Beyond factual collaboration, the interdependence with public authorities lies also in the fact that across the three fields, most of the interviewed organisations are financed by public money through income-tax donations (a specific measure of the Italian fiscal system designed to

${ }^{20}$ Migr1 07/2016. 
support civil society and religious organisations). Noticeably, however, public funds are not exclusive and in several cases not even the most relevant forms of financing, such as banking foundations' donations, membership fees, fundraising events (in the disability and migration area), crowdfunding and participation in public tenders (in the migration field, with the exception of one interviewee who stated that they refuse to be funded by public authorities, preferring to maintain their independence) are concurrent sources of funds and resources. Finally, most of the TSOs in the unemployment area (especially cooperatives) support their activities through the market.

\section{Transnational Cooperation}

Systematically collaborating with foreign or international entities is quite rare among the interviewees. Indeed, few TSOs have stable international linkages (except those in the migration field), but most have participated in ad hoc European/international projects or have indirect linkages to European/supranational networks through national organisations to which they belong. Small TSOs have more difficulties in developing international activities. The most important factor for supranational connections seems to lie in the TSOs' size and not their institutionalisation: Indeed, one of the most active TSOs at the international level is a large informal grassroots group. Curiously, despite their inability to maintain stable transnational collaborations, all the TSOs acknowledge the importance of transnational solidarity (especially in the migration field). ${ }^{21}$

As was the case for the large majority of the analysed aspects, each issue-field shows its specificity for transnational engagement. TSOs in the migration area are those that have more stable international linkages: Most of the organisations cooperate in a structured way with organisations based abroad; they participate in projects in other European or nonEuropean countries, or they belong to transnational organisations. The international collaborations are developed with diverse foreign partners:

\footnotetext{
21 "The problem is European and it is important to create European networks to exchange information and best practices, to share responsibilities [...]. Although sometimes there is no unity in terms of claims and political vision" (Migr8 10/2016).
} 
NGOs, cooperatives and Caritas, transnational NGOs such as "Doctors Without Borders", grassroots informal groups and platforms like "Welcome to Europe".

Conversely, small voluntary non-profit organisations have only occasional exchanges with foreign partners (or some of their members participate individually in international activities), or they are included in international networks through umbrella organisations of which they are members.

Solidarity in itself is conceived in international terms in the field of migration, as the European level is perceived crucial for any policyoriented mission. ${ }^{22}$

The local level is important because integration takes place at the local level. The European level is important for orientation, information exchange, advocacy, exchange of good practices. (Migr7 10/2016)

We have to start from the local level, but then we need to take action on several levels [...] Solidarity must be transnational [...] Freedom of movement for all. (Migr4 09/2016)

TSOs in both disability and unemployment areas do not cooperate in a structured manner with foreign organisations. Occasionally, they participate in ad hoc projects in other countries or, in the case of the most institutionalised organisations, have indirect international linkages through national organisations to which they belong.

Those who have directly participated in European projects stress the importance of transnational solidarity interlinkages:

The idea of exiting the 'already known' is important. It was positive to capitalise on our experience by creating partnerships with foreign experiences. (Disab6 10/2016)

Even if most of these TSOs are not directly active abroad, they recognise the importance of transnational cooperation, claiming that solidarity

\footnotetext{
22 "The sole local and national levels are not sufficient. European campaigns on migrants are needed" (Migr6 10/2016).
} 
with disabled people or with the unemployed and workers should not be restrained to local or national levels, but should also take place at the European and international levels. In the two domains, the supranational dimension as an arena for policy advocating is much less relevant than in the migration field. ${ }^{23}$ For disability and unemployment TSOs, having transnational networks represents, first of all, a source of exchange and lesson-learning occasion:

Through comparison with other countries, it is possible to improve what is done locally ... for example, what concerns the architectural barriers... (Disab5 10/2016)

It would be better to develop international collaboration to have better knowledge of neighbouring regions and to share information on best practices. (Disab7 10/2016)

It is important to create networks of solidarity and action at an international level $[\ldots]$. The cooperative movement is grounded in the value of solidarity. (Unemp6 10/2016)

However, many TSOs are small associations and this is a problem for the development of strong transnational solidarity networks:

A transnational network would be useful, but our cooperative is too small. (Unemp5 10/2016)

They all, regardless of their policy domain, emphasise that the path to international solidarity is still very long and hard (and some maintain that this is the case at the national level, too).

\footnotetext{
${ }^{23}$ But with some interesting exceptions, as "Unity is strength. 'A nut in a bag does not make noise" (Disab8 10/2016), and "National policies are fundamental, but it is necessary to have more and more transnational regulatory mechanisms" (Unemp2 09/2016).
} 


\section{Conclusions: Main Findings and Implications}

The disability TSOs we spoke with are more help/service-oriented; even though many of them are also interested in lobbying and advocacy, they mainly follow a top-down approach of providing services to their beneficiaries while creating solidarity relations based on mutual help and support. In this policy domain, the internal variability is lower than in the other two fields and especially, if compared to the unemployment field, where there is a clearer distinction between help/service-oriented TSOs and protest/policy-oriented TSOs. In the unemployment area, unions (of workers or cooperatives) are focused more on lobbying than on help, whereas social cooperatives and religious organisations are help/ service-oriented.

Contentious TSOs are present in the field of both unemployment and migration but absent in the field of disability, where a more pragmatic, non-politicised approach prevails. A clear left-wing orientation emerges, conversely, among some TSOs in the unemployment and migration fields. In the former, some TSOs explicitly aim at social justice, intergenerational mutualism, equal opportunities, economic democracy and labour empowerment. In the latter, many TSOs present a universalistic conception of solidarity_ “solidarity for all human beings" (Arendt 1972; Brunkhorst 2005) — based on social justice and rights vindication.

All our interviewees stress the negative consequences of the crisis in terms of cuts to the welfare state, reduction of funds (also from private donors) and increasing inequality. Most of the interviewees strongly criticise the austerity measures enacted to face the crisis, with severe consequences, especially for disadvantaged people. Furthermore, the crisis resulted in cuts in public investments and investments in innovation: Entrepreneurs were not willing to take the risk of innovation and this had a devastating impact on the labour market. Moreover, the crisis has led to short-term political intervention for reasons of consensus, at the expense of longer-term goals:

But innovation requires a longer time-span than the five year mandate of the mayor! The crisis could have been the occasion for a radical re- 
foundation of our society, but unfortunately, it has not happened. (Migr3 09/2016)

And yet, most of the TSOs perceive the crisis as an opportunity to reconsider their views, to innovate and to increase cooperation between associations. As regards the latter aspect, the crisis incentivised, for instance, TSOs in the disability field, to collaborate and share resources, thus overcoming the excessive parochialism that has long characterised the field dominated by highly disability/disease-specialised organisations. Services offered to disabled persons have also become much more oriented towards their actual needs. Moreover, in several disability TSOs, the disabled are no longer treated as passive beneficiaries. Instead, they are increasingly involved as active participants in the various aspects of the association's life. This development suggests a shift from a top-down charity perspective to more equality- and empowerment-oriented relations "at eye-level". Sometimes, the crisis also led to solidarity-based practice innovations, like the "pact" between some Italian and Greek social movements: material support and help in exchange for a new repertoire of actions and fresh information. The crisis, to a certain extent, has been a trigger and an opportunity for organisational learning and for expanding collaborative networks between civil society organisations (also Carley and Harrald 1997; Shahin et al. 2013).

The in-depth interviews confirm, therefore, our principal assumption that solidarity attitudes, practices, discourses and actions are strongly influenced by the policy domain in which the TSOs are active. Despite a number of similarities, our data suggest that the field of activity strongly determines TSOs nature and activities (see also Warren 2001). These field-specific differences might be explained in a threefold way. Firstly, the type of vulnerabilities and beneficiaries is important in itself: It makes a difference whether one is disabled (with a specific deficiency) or unemployed or a migrant in terms of approach and type of actions that TSOs have to adopt to deal with specific needs and differentiated demands for social protection. Secondly, field-specific differences are shaped by the historic legacies of TSOs within different organisational fields. For instance, path-dependency is clear as regards the more fractionalised history of disability TSOs, or the higher degree of politicisation of 
unemployed TSOs: The former potentially stems from the tradition of disabled self-help groups, whereas for the latter, the role played by unionisation is key. Thirdly, across-field (and sometimes within-field) fragmentation is strengthened by public policies framing fields of activity externally. In this regard, political opportunity structure literature (Kriesi 2004; Tilly and Tarrow 2006; Cinalli and Giugni 2011, 2014) has stressed how civil society organisations' activities do not occur in a vacuum; conversely, they are likely to be influenced by specific characteristics of the context (including public policies) in which they operate.

In contrast, our findings provide a more mixed picture as regards the second hypothesis about the crisis being a vector of both innovation and transnationalism. According to the insights we gained, these two aspects have to be treated in a more differentiated way. As previously mentioned, the research results clearly show that the crisis has obliged the TSOs we spoke with to change: either extending their range of action or increasing the number of their beneficiaries, either searching for different solutions to new needs or modifying their repertory of actions, as stressed also by other studies (Forno and Graziano 2014; Bosi and Zamponi 2015). Our interlocutors have defined these changes in terms of innovation; therefore, we shall conclude that the crisis led TSOs to search for new strategies and new approaches, even though innovation does not necessarily lie at the centre of all our TSOs' interests. Discussing whether these new strategies and approaches are truly innovative per se is more complex, and it is beyond the scope of our research at this stage. In any case, our results are in line with those of several empirical studies on solidarity initiatives both in Italy and in Europe that have stressed how austerity and cuts led not only to anti-austerity protests but also to resilience, social ingenuity and social innovations (Andretta and Guidi 2014; Forno and Graziano 2014; Grasseni 2014; Kousis and Paschou 2017; Oliveri 2015; Kousis et al. 2018; Lahusen et al. 2016).

In comparison, effective transnational solidarity actions remain marginal, even if transnationalism is recognised as the appropriate dimension for solidarity strategies, practices and policy-making. In fact, very few interviewees affirm that they regularly collaborate with foreign partners. The large majority of interviewed TSOs lacks the resources and skills to develop international partnerships and does not go beyond mentioning 
the theoretical importance of transnational solidarity and supranational responsibilities. In times of multiple domestic crises, responding to local and regional needs and demands has top priority, leaving little room for engaging in more far-reaching transnational activities. From this perspective, our study suggests that the crisis was not an effective vector of transnationalisation of Italian civil society activism in the three analysed fields of vulnerability.

\section{References}

Alexander, E. R. (1995). How Organizations Act Together: Interorganizational Coordination in Theory and Practice. Luxembourg: Gordon and Breach Publishers.

Andretta, M., \& Guidi, R. (2014). Resilience and Positive Protest. How Italian Solidarity-Based Purchase Groups Change in Times of Crisis and Austerity?. Paper for the XXVII SISP Conference - Section no. 6.

Arendt, H. (1972). Crises of the Republic. New York: Harcourt Brace Jovanovich. Ataç, I., Rygiel, K., \& Stierl, M. (2016). Introduction: The Contentious Politics of Refugee and Migrant Protest and Solidarity Movements: Remaking Citizenship from the Margins. Citizenship Studies, 20(5), 527-544.

Baglioni, S., \& Giugni, M. (2014). Civil Society, Unemployment and Precarity in Europe: An Introduction. In S. Baglioni \& M. Giugni (Eds.), Civil Society Organizations, Unemployment, and Precarity in Europe. Between Service and Policy (pp. 1-10). London: Palgrave Macmillan.

Banfield, E. C. (1967). The Moral Basis of a Backward Society. With the Assistance of Laura Fasano Banfield. Glencoe: Free Press.

Bosi, L., \& Zamponi, L. (2015). Direct Social Actions and Economic Crises: The Relationship between Forms of Action and Socio-Economic Context in Italy. Partecipazione e Conflitto, 8(2), 367-391.

Brunkhorst, H. (2005). Solidarity. From Civic Friendship to Global Legal Community. Cambridge, MA: Cambridge University Press.

Carley, K. M., \& Harrald, J. R. (1997). Organizational Learning Under Fire. The American Behavioral Scientist, 40(3), 310-332.

Cinalli, M., \& Giugni, M. (2011). Institutional Opportunities, Discursive Opportunities, and the Political Participation of Migrants in European Cities. In L. Morales \& M. Giugni (Eds.), Social Capital, Political Participation and Migration in Europe (pp. 43-62). London: Palgrave Macmillan. 
Cinalli, M., \& Giugni, M. (2014). The Impact of Political Opportunity Structures on the Politicization of Civil Society Organizations in the Field of Unemployment and Precarity. In S. Baglioni \& M. Giugni (Eds.), Civil Society Organizations, Unemployment, and Precarity in Europe. Between Service and Policy (pp. 85-106). London: Palgrave Macmillan.

Forno, F., \& Graziano, P. (2014). Sustainable Community Movement Organisations. Journal of Consumer Culture, 14(2), 139-157.

Grasseni, C. (2014). Seeds of Trust. Italy's Gruppi di Acquisto Solidale (Solidarity Purchase Groups). Journal of Political Ecology, 21, 178-192.

Kousis, M., \& Paschou, M. (2017). Alternative Forms of Resilience. A Typology of Approaches for the Study of Citizen Collective Responses in Hard Economic Times. Partecipazione e Conflitto, 10(1), 136-168.

Kousis, M., Giugni, M., \& Lahusen, C. (2018). Action Organization Analysis: Extending Protest Event Analysis Using Hubs-Retrieved Websites. American Behavioral Scientist, 62(6), 739-757.

Kriesi, H. (2004). Political Context and Opportunity. In D. A. Snow, S. Soule, \& H. Kriesi (Eds.), The Blackwell Companion to Social Movements (pp. 67-90). Oxford: Blackwell.

Lahusen, C., Loukakis, A., \& Kiess, J. (2016). Spatial Patterns of Alternative Action Organizations in Europe: Building Resilience in Times of Crisis Where It Is Needed?. Conference paper for the ECPR General Conference Panel, Transnational Solidarity and Alternative Action Organizations in European Countries at Times of Crisis, Open Section, Prague, September 7-10.

Maggini, N., \& Federico, V. (2016). Italy. In TransSOL (Eds.), Integrated Report on Reflective Forms of Transnational Solidarity, Part III. Qualitative Interviews with Representatives of Innovative Transnational Solidarity Organisations (pp. 203-225). Retrieved from http://blogs.uni-siegen.de/transsol/ files/2016/12/Integrated-Report-on-Reflective-Forms-of-TransnationalSolidarity.pdf

McRuer, R. (2010). Disability Nationalism in Crip Times. Journal of Literary \& Cultural Disability Studies, 4(2), 163-178.

Oliveri, F. (2015). A Network of Resistances Against a Multiple Crisis. SOS Rosarno and the Experimentation of Socio-Economic Alternative Models. Partecipazione e Conflitto, 8(2), 504-529.

Shahin, J., Woodward, A., \& Terzis, G. (2013). The Impact of the Crisis on Civil Society Organisations in the EU: Risks and Opportunities. Brussels: European Economic and Social Committee. Retrieved from: http://ec.europa.eu/citizenship/pdf/eesc_qe-32-12-548-en-c_en.pdf 
Shildrick, M. (2009). Dangerous Discourses of Disability, Subjectivity and Sexuality. Abingdon: Palgrave Macmillan.

Soldatic, K., \& Grech, S. (2014). Transnationalising Disability Studies: Rights, Justice and Impairment. Disability Studies Quarterly, 34(2), 33. 1 p.

Tilly, C., \& Tarrow, S. (2006). Contentious Politics. London: Paradigm.

TransSOL. (2016). Work Package 2 Integrated Report on Reflective Forms of

Transnational Solidarity. Retrieved from http://blogs.uni-siegen.de/transsol/ files/2016/12/Integrated-Report-on-Reflective-Forms-of-TransnationalSolidarity.pdf

Warren, M. E. (2001). Democracy and Association. Princeton: Princeton University Press.

Open Access This chapter is licensed under the terms of the Creative Commons Attribution 4.0 International License (http://creativecommons.org/licenses/ by/4.0/), which permits use, sharing, adaptation, distribution and reproduction in any medium or format, as long as you give appropriate credit to the original author(s) and the source, provide a link to the Creative Commons licence and indicate if changes were made.

The images or other third party material in this chapter are included in the chapter's Creative Commons licence, unless indicated otherwise in a credit line to the material. If material is not included in the chapter's Creative Commons licence and your intended use is not permitted by statutory regulation or exceeds the permitted use, you will need to obtain permission directly from the copyright holder.

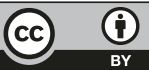

